\title{
Clinico-Functional Characteristics of Left Ventricular Dysfunction in Patients with Glomerulopathies and Their Relationship to Morphological Changes in The Kidneys
}

\author{
Aiypova Dinara ${ }^{*}$, Beishebaeva Nasira², Sarybaev Akpay ${ }^{3}$ and Kaliev Rysbaek ${ }^{4}$ \\ ${ }^{1}$ Research Fellow, Department of Nephrology, National Center of Cardiology and Internal Medicine (NCCIM)
}

${ }^{2} \mathrm{PhD}$, Head of Nephrology Department

${ }^{3}$ Professor of department of Head of the Pulmonary Hypertension, Mountain and Sleep Medicine Department of NCCIM

${ }^{4}$ Professor of department of Faculty Therapy, Kyrgyz State Medical Academy

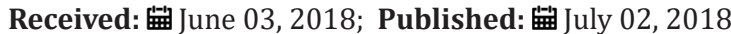

*Corresponding author: Ayipova Dinara, Research Fellow, Department of Nephrology, National Center of Cardiology and Internal Medicine, Kyrgyzstan

\section{Abstract}

Purpose: To study the possible association of cardiac function with morphological changes of the kidneys in glomerulopathies.

Materials and Methods: 55 patients with GP were examined (32 men, 23 women) aged from 17 to 58 (on the average $32.76 \pm$ 10.3) years. Given the high prevalence left ventricular systolic diastolic dysfunction in patients with GP with impaired renal function, analyzed the data of patients with CKD stages 1-3. The mean GFR was $87.92 \pm 28.2 \mathrm{ml} / \mathrm{min} / 1.73 \mathrm{~m} 2$. Histology, immunofluorescence and electron microscopic method of investigation were used in the study of nephrobiopsy data.

Results: Analysis of the frequency of morphological types of nephropathy in the examined patients made it possible to detect the prevalence of membranous glomerulonephritis (MG), which accounted for $43.6 \%$ of observations. IgA nephropathy was detected in $36.4 \%$ of cases. Focal-segmental glomerulosclerosis and minimal-change disease were much less common and in an equal proportion $(7.3 \%$ of cases). Less often (in 5,4\%) was marked by membrane-proliferative glomerulonephritis. Damage to glomerulus and endothelial proliferation significantly influenced the delay in the flow of early diastolic filling of the left ventricle deceleration and isovolumic relaxation time.

The Conclusion: The causes of the development of diastolic dysfunction of the heart are the damage of glomerulus, endothelial proliferation, deposits of the complement fraction C3 in GP.

Chronic kidney disease (hereinafter CKD) is an actual medical and social problem all over the world due to its significant increase in prevalence and adverse outcomes [1]. The mortality from cardiovascular diseases (hereinafter CVD) in patients with CKD is 1530 times higher than in the general population [2,3]. The achievements of modern nephrology have identified new approaches to the clinical analysis of complications of glomerulopathies (HP). A comparison of the CKD clinic with the frequency of complications showed that $74 \%$ of patients starting dialysis treatment are diagnosed with cardiac pathology [4]. So, in the work of Paoletti E [5] there is a decrease in survival due to an increase in the number of fatal and non-fatal complications in the presence of CVD in patients with chronic renal insufficiency. As for the pre-dialysis population, Weiner DE [6] analysis of four large studies (2,423 patients), with the definition of glomerular filtration rate (GFR) (15 to $60 \mathrm{~mL} / \mathrm{min} / 1.73 \mathrm{~m} 2$ ) showed the dependence of the mortality rate on CVD in patients with CKD. In a study by Cai Q Z [7] significant changes in the side of deterioration of the cardiac structure were detected already in the first year of the disease in patients with CKD 3-5 stages. The authors explain this fact by the prolonged increase in the mass and volume of the left ventricle (LV) and the presence of diastolic (LVDM), rather than systolic LV dysfunction (LVDS). In the experimental work of Li K-L [8] it was found that maintaining normal diastolic function of the left ventricle in patients with CKD prevented the appearance of heart failure with reduced renal function. Modern methods of nephrobiopsy and 
improvement of immunomorfologic methods of analysis have opened the possibility to the study of live morphology of the kidney tissues more deeply, as well as to determine the role of the immune mechanism in the development of complications, including CVD [9]. Thanks to these data, the treatment of the disease, approaches to therapy and prevention of complications will change in the future [9]. However, at present, there are many unsolved issues in this area. There is still no clear correlation between clinical data and morphological manifestations of GP.

Objective: To study the features of the association of cardiac dysfunction with morphological changes in the kidneys with HP.

Abbreviations: CKD: Chronic Kidney Disease; GFR: Glomerular Filtration Rate; ECHOKG: Echocardiography; DBP: Diastolic Blood Pressure; SBP: Systolic Blood Pressure; FSG: Focal-Segmental Glomerulosclerosis; IMC: Minimal-Change Disease; MPGN: MembraneProliferative Glomerulonephritis

\section{Materials and Methods}

55 patients with GP were examined ( 32 men, 23 women) aged from 17 to 58 (on the average $32.76 \pm 10.3$ ) years. The glomerular filtration rate (GFR) was calculated by CKD-EPI (2013), and the CKD stages were determined according to NKF K / DOQI, Guidelines, 2002 [10]. Given the high prevalence of LVDS and LVDM in patients with CKD with reduced renal function, we analyzed the data of patients with CKD 1-3 stages. The mean GFR was $87.92 \pm 28.2 \mathrm{ml} /$ $\mathrm{min} / 1.73 \mathrm{~m} 2$. All patients underwent a complex of general clinical, biochemical, bacteriological, immunological, instrumental and morphological studies. General clinical methods included general analyzes of urine, blood and daily proteinuria. Echocardiography (ECHOKG) study was carried out according to the standard procedure on the "CX50 CompactXtreme Ultrasound System" with the identification of a complex of generally accepted morphofunctional parameters. To evaluate the diastolic function of the $\mathrm{LV}$, a transmittal flow from the apical access in the 4-chamber section was examined, and tissue myocardial Doppler echocardiography.

\section{Histopathological Analysis}

In the study of nephrobiopsy, histological, immunofluorescent and electron microscopic methods were used. For the diagnosis of forms of GB, conventional morphological criteria were used [10]. The conclusion on the study of nephrobiopsy was established according to a single terminology in describing the pathological process and the morphological classification of the ICD X revision. In morphological analysis of glomerular changes the size of the glomerulus, the presence (degree) or absence of proliferation of mesangial cells and glomerular capsule epithelium, the state of the mesangial matrix and the structure of the basal membrane (thickening, uneven contours, splitting) are described. The algorithm of studying the kidney biopsy covered information on interstitial tissue (fibrosis, edema, infiltration) and the presence of adhesions (atrophy, dystrophy, necrosis). Morphological signs of the activity of the process included such processes as protein exudation in the lumen of the capsule, plethora of capillaries, plasmorragia, fixation on the basal membranes of glomerular capillaries and in the mesangium of immunoglobulins and fibrinogen. The statistical processing of the material was carried out using the Statistica 6.0 statistical software package. The results are processed using multivariate stepwise regression analysis. Differences were considered statistically significant at $\mathrm{p}<0.05$.

\section{Results and Discussion}

In most patients $(78.1 \%)$, the disease made its debut at the age of over 17, which is consistent with the literature data $[11,12]$. Clinically, most often there was a nephrotic syndrome (65.4\%) and in most cases men (72.2\%). Mean levels of systolic blood pressure (SBP) and diastolic blood pressure (DBP) were $130.3 \pm 20.0 \mathrm{~mm}$ $\mathrm{Hg}$ and $83.2 \pm 13.06 \mathrm{~mm} \mathrm{Hg}$, respectively. At the first stage of the study of our patients, the morphological characteristics of the GP is studied. Analysis of the frequency of various morphological forms of nephropathy in the subjects allowed to reveal the prevalence of membranous glomerulonephritis $(\mathrm{MH})$, which accounted for $43.6 \%$ of observations. IgA nephropathy was detected in $36.4 \%$ of cases of primary HP. Among the subjects, focal-segmental glomerulosclerosis (FSG) and minimal-change disease (IMC) were encountered much more rarely and with an equal share $(7.3 \%$ of cases). Less often $(5,4 \%)$ was marked by membrane-proliferative glomerulonephritis (MPGN).

Light-optically glomerular changes were manifested in the form of minimal damage in $23.6 \%$, segmental sclerosis in $41.8 \%$ and endothelial proliferation in $14.5 \%$ of cases. The occurrence of mesangial hypercellularity in the examined patients was $50 \%$, the expansion of mesangium was $38.1 \%$. In $52.7 \%$ of the patients, there were tubular injuries in the form of tubular atrophy, as well as interstitial fibrosis. Immunohistological examination of IgG was found in $43.6 \%$, IgA - in $36.4 \%$ and IgM - in $20 \%$ of cases, and they had a granular distribution. Such a presence of deposits on the basement membrane of glomerular capillaries testified to the immune nature of kidney damage. Electron microscopy in $72.7 \%$ of cases recorded the merging of the legs of podocytes, and in $21.8 \%$ - mesangial expansion.

At the second stage of our work, we studied the factors that influence to the clinical picture of glomerulopathies. A multifactorial stepwise regression analysis was performed, where as independent variables included the indices of morphological changes in the nephrobioptate, as well as varieties of immunocomplexes. As dependent variables, the parameters of the general analysis and biochemistry of blood, as well as the echocardiographic parameters (systolic, diastolic function of the heart) were alternately included. We tried to analyze the relationship between the state of the filtration function of the kidneys and the immunological situation 
in the glomeruli. It turned out that in the general sample of patients, the presence of IgG ( R2 $=0.44, \mathrm{P}<0.001)$ was a significant factor that adversely affected the value of RSKF. The presence of IgG in the composition of glomerular deposits, respectively, and reflected at the level of creatinine (R2 $=-0.45, \mathrm{P}<0.0007)$. Reliable statistical results of our study indicate that the presence of immunoglobulins in the glomeruli reflects the severity of the nephritis. The ratio of histological changes and indices of proteinuria and blood tests are presented in Table 1.

Table 1: Morphological indicators, associated with clinicbiochemical sizes of blood.

\begin{tabular}{|c|c|c|c|}
\hline $\begin{array}{c}\text { Significantly related } \\
\text { independent variable }\end{array}$ & $\begin{array}{l}\text { Dependent } \\
\text { variable }\end{array}$ & $\mathbf{R}^{2}$ & $\mathbf{P}>$ \\
\hline $\begin{array}{l}\text { Mesangial hypercellularity } \\
\text { Proteinuria }\end{array}$ & Proteinuria & $-0,29$ & 0,04 \\
\hline Segmental sclerosis & $\begin{array}{c}\text { albumen } \\
\text { protein }\end{array}$ & 0,47 & 0,0007 \\
\hline Expansion of mesangium & GFR & 0,29 & 0,04 \\
\hline \multirow{2}{*}{$\begin{array}{l}\text { Tubular atrophy / interstitial } \\
\text { fibrosis }\end{array}$} & HB & 0,32 & 0,02 \\
\hline & Leukocytes & 0,41 & 0,003 \\
\hline C3 & antistreptolisin & $-0,45$ & 0,03 \\
\hline \multirow[t]{2}{*}{$\operatorname{Ig} A$} & $\begin{array}{c}\text { albumen } \\
\text { protein }\end{array}$ & 0,28 & 0,04 \\
\hline & Albumen & 0,36 & 0,01 \\
\hline \multirow{4}{*}{$\operatorname{IgG}$} & Creatinine & $-0,45$ & 0,0007 \\
\hline & GFR & 0,44 & 0,001 \\
\hline & Cholesterol & 0,30 & 0,03 \\
\hline & ESR & 0,41 & 0,002 \\
\hline
\end{tabular}

Note: AP - albumen protein; GFR - glomerular filtration rate; Нв - haemoglobin; АСЛО - antistreptolisin; СОЭ - скорость оседания эритроцитов.

As follows from Table 1, there was a clear connection between the morphological pattern of changes in the renal parenchyma and a number of blood indicators reflecting the GP clinic. The effect of segmental sclerosis on the amount of serum protein was demonstrated by direct regression analysis $(\mathrm{R} 2=0.47, \mathrm{P}$ $<0.0007$ ). To explain this situation, the following point of view seems appropriate: the detected changes in the glomeruli reflect significant damage to the glomerular filter, which create conditions for pronounced proteinuria and a change in the colloidal stability of the blood plasma [13]. Further, as can be seen from Table 1, the changes in mesangium included in the final model of multiple stepwise linear regression significantly influenced the calculated index of renal function ( $R 2=-0.29, \mathrm{P}<0.04)$. By analogy with the above, a reliable relationship was found when comparing mesangial hyper cellularity and proteinuria $(\mathrm{R} 2=-0.29, \mathrm{P}<0.04)$. Of no little importance was the study of the condition of the tubules. In general, we received evidence in favor of the presence of a relationship between tubular atrophy (TA), interstitial fibrosis (IF) and hemoglobin level in the blood (R2 $=0.32, \mathrm{P}<0.02)$. This phenomenon explains the fact that the severity of anemia in $\mathrm{HH}$ depends on the depth of damage of interstitial kidneys, since it is here that the formation of erythropoietins occurs.

Table 2: Morphological variables associated with arterial pressure.

\begin{tabular}{|c|c|c|c|}
\hline $\begin{array}{c}\text { Dependent } \\
\text { variable }\end{array}$ & $\begin{array}{c}\text { Significantly related } \\
\text { independent variable }\end{array}$ & $\mathbf{R}^{\mathbf{2}}$ & $\mathbf{P}>$ \\
\hline \multirow{2}{*}{ SBP } & Ig G & 0,32 & 0,02 \\
\cline { 2 - 4 } & Ig A & $-0,29$ & 0,03 \\
\cline { 2 - 4 } & Damage to the glomerulus & 0,42 & 0,002 \\
\hline \multirow{2}{*}{ DBP } & $\begin{array}{c}\text { Tubular atrophy / interstitial } \\
\text { fibrosis }\end{array}$ & 0,34 & 0,01 \\
\cline { 2 - 4 } & Ig M & 0,27 & 0,04 \\
\cline { 2 - 4 } & Ig A & $-0,28$ & 0,04 \\
\hline
\end{tabular}

Note: SBP - systolic AD, DBP - diastolic blood pressure.

As for the ratio of immunohistology and blood pressure (Table 2 ), we found a significant relationship between the presence of TA / IF and DBP (R2 $=0.34, \mathrm{P}<0.01)$. It should be noted that in patients with TA/IF arterial hypertension (AH) was a consequence of tubulopathy, not nephrosclerosis. Our results are consistent with the data of Kotaro Haruhara et al. [14] who conducted a study of the relationship of tubulopathy and $\mathrm{AH}$ in patients with IgA nephropathy. We found the same pattern when comparing the parameters of damage to glomerulus and AH $(\mathrm{R} 2=0.42, \mathrm{P}$ $<0.002$ ). The established dependence testified to the leading role of endothelial dysfunction in the development of arterial hypertension. This information is consistent with the data of Salmon AH et al. $[15,16]$ who believe that proteinuria, as a consequence of damage of glomerulus, is considered a marker of endothelial dysfunction and glomerular hyperfiltration. At the same time, damage to glomerulus and endothelial proliferation (Table 3) caused a slowing of the time of blood flow of early diastolic filling of the left ventricle (DT) and isostolic LV relaxation (IVRT) (R2 $=0.31, \mathrm{P}<0.03$ and R2 $=0.32, \mathrm{P}<0.02$, respectively). Significant shifts in parameters of $\mathrm{LV}$ relaxation function were due to the appearance of complement fractions in the composition of immune deposits in capillaries C3. Therefore, the results obtained by us indicate an early renocardial interaction. Here, probably not final role-plays the presence of an inflammatory process, which leads to the development of diastolic dysfunction [17]. The pathomorphism of nephropathy is manifested by the development of systolic LV dysfunction [18] of great interest was the question of the effect of immune complexes on the architecture of the heart. Analysis of the parameters of our patients Table 4 showed a significant effect of IgM on systolic LV volume (SLV), thickness of interventricular septum (TMV) and the anterior wall of the right ventricle (PSP) $(\mathrm{R} 2=0.29, \mathrm{P}<0.03, \mathrm{R} 2=$ $0.47, \mathrm{P}<0.0006, \mathrm{R} 2=0.29, \mathrm{P}<0.03$, respectively). Similar results were obtained in the study of the effect of complement on the heart. Thus, the dependence of the thickness of the walls of SLV, TIS on the $\mathrm{C} 3$ fraction of the complement fraction $(\mathrm{R} 2=0.33, \mathrm{P}<0.01, \mathrm{R} 2=$ $0.39, \mathrm{P}<0.006$, respectively) has been elucidated. Consequently, the 
appearance of immune deposits under the capillary endothelium is systemic.

Table 3: Morphological features associated with parameters diastolic relaxation of the $\mathrm{LV}$.

\begin{tabular}{|c|c|c|c|}
\hline $\begin{array}{c}\text { Dependent } \\
\text { variable }\end{array}$ & $\begin{array}{c}\text { Significantly related } \\
\text { independent variable }\end{array}$ & $\mathbf{R}^{2}$ & $\mathbf{P}>$ \\
\hline DT & Damage to the glomerulus & 0,31 & 0,03 \\
\hline IVRT & Endothelial proliferation & 0,32 & 0,02 \\
\hline E/A & C3 & $-0,30$ & 0,03 \\
\hline A' & C3 & 0,30 & 0,03 \\
\hline A & C3 & 0,30 & 0,03 \\
\hline
\end{tabular}

Note: DT - the time to slow the blood flow of early diastolic filling of the left ventricle; IVRT - the time of isovolytic relaxation of the left ventricle; E / A - the ratio of early to late diastolic filling, $\mathrm{A}^{\prime}$ - late diastolic movement of the medial part of the mitral ring; A - late diastolic filling; C3 - complement.

Table 4: Immunomorphological findings associated with the parameters of the structure of the myocardium.

\begin{tabular}{|c|c|c|c|}
\hline $\begin{array}{c}\text { Significantly related } \\
\text { independent variable }\end{array}$ & $\begin{array}{c}\text { Dependent } \\
\text { variable }\end{array}$ & $\mathbf{R}^{\mathbf{2}}$ & $\mathbf{P}>$ \\
\hline \multirow{3}{*}{ IgM } & SLV & 0,29 & 0,03 \\
\cline { 2 - 4 } & TIS & 0,47 & 0,0006 \\
\cline { 2 - 4 } & AWRV & 0,29 & 0,03 \\
\hline \multirow{2}{*}{ C3 } & SLV & 0,33 & 0,01 \\
\cline { 2 - 4 } & TIS & 0,39 & 0,006 \\
\hline
\end{tabular}

Note: SLV - systolic LV volume, TIS - thickness of the interatrial septum; AWRV - the anterior wall of the right ventricle.

\section{Conclusion}

a. Tubular atrophy and interstitial fibrosis are involved in the development of arterial hypertension in patients with HP.

b. Damage to glomerulus, endothelial proliferation, deposits of the complement $\mathrm{C} 3$ fraction in the vessels are presumably the cause of diastolic dysfunction.

c. The deposition of the IgM and C3 complement fraction in the capillaries are systemic and affect the size of the heart.

\section{References}

1. Schieppati A, Remuzzi G (2005) Chronic renal diseases as a public health problem: epidemiology, social and economic implications. Kidney Int Supp (98): 7-10.

2. De Jager DJ, Grootendorst DC, Jager KJ (2009) Cardiovascular and noncardiovascular mortality among patients starting dialysis. JAMA 302(16): 1782-1789.
3. Ross L, Banerjee D (2013) Cardiovascular complications of chronic kidney disease. Int J Clin Pract 67(1): 4-5.

4. Bradbury BD, Fissell RB, Albert JM (2007) Predictors of early mortality among incident US hemodialysis patients in the Dialysis Outcomes and Practice Patterns Study (DOPPS). Clin J Am Soc Nephrol 2(1): 89-99.

5. Paoletti E, Bellino D, Gallina AM (2011) Is left ventricular hypertrophy a powerful predictor of progression to dialysis in chronic kidney disease? Nephrol Dial Transplant 26(2): 670-677.

6. Weiner DE, Tighiouart H, Vlagopoulos PT (2005) Effects of anemia and left ventricular hypertrophy on cardiovascular disease in patients with chronic kidney disease. J Am Soc Nephrol 16(6): 1803-1810.

7. Cai QZ, Lu XZ, Lu Y, Wang AY M (2014) Longitudinal Changes of Cardiac Structure and Function in CKD (CASCADE Study). Journal of the American Society of Nephrology, JASN 25(7): 1599-1608.

8. Li K-L, Wang R-X, Dai M, Lu J (2015) Antihypertensive treatment improves left ventricular diastolic function in patients with chronic kidney disease. Experimental and Therapeutic Medicine 9(5): 17021708.

9. Varshavski VA, Golizyna EP, Stoliarevich ES, Palzeva EM (2014) Morphological criteria for the progression of chronic kidney diseases. Nephrology. National leadership. Ch. Mukhin NA (Eds.), GEOTAR-Media, Moscow, Russia.

10. (2002) National Kidney Foundation K/DOQI Clinical Practice Guidelines for Chronic Kidney Disease: Evaluation, classification, and stratification. Am J Kidney Dis 39: S1-266.

11. (2014) Morphological criteria for the progression of chronic kidney diseases. Nephrology. National leadership. Ch. Mukhin NA (Eds.) GEOTAR-Media, Moscow, Russia.

12. Khasabov NN, Malkoch AV (2005) Modern concepts of glomerulonephritis. Nephrology of childhood (edited by VA Tabolin and others). MID Medpraktika-M, pp. 306-390.

13. Johnson RJ, Herrera Acosta J, Schreiner GF (2002) Subtle acquired renal injury as a mechanism of salt-sensitive hypertension. N Engl J Med 346(12): 913-923.

14. Kotaro Haruhara, Nobuo Tsuboi, Kentaro Koike (2015) Ambulatory blood pressure and tubulointerstitial injury in patients with IgA nephropathy. Clinical Kidney Journal 8(6): 716-721.

15. Salmon AH, Ferguson JK, Burford JL (2012) Loss of the endothelial glycocalyx links albuminuria and vascular dysfunction. J Am Soc Nephrol 23(8): 1339-1350.

16. Salmon AH, Satchell SC (2012) Endothelial glycocalyx dysfunction in disease: albuminuria and increased microvascular permeability. J Pathol 226(4): 562-574.

17. Thomson NM, Charlesworth J (1995) Classification, pathology and clinical features: Primary glomerulonephritis, in Textbook of Renal Disease ( $2^{\text {nd }}$ edn.), edited by Whitworth J, Lawrence J, Edinburgh, Churchill Livingstone, pp. 129-157.

18. Gromadziński L, Pruszczyk P (2014) Echocardiographic Changes in Patients with Stage 3-5 Chronic Kidney Disease and Left Ventricular Diastolic Dysfunction. Cardiorenal Medicine 4(3-4): 234-243. 
This work is licensed under Creative Commons Attribution 4.0 License

To Submit Your Article Click Here:

Submit Article

DOI: $10.32474 / J U N S .2018 .01 .000105$

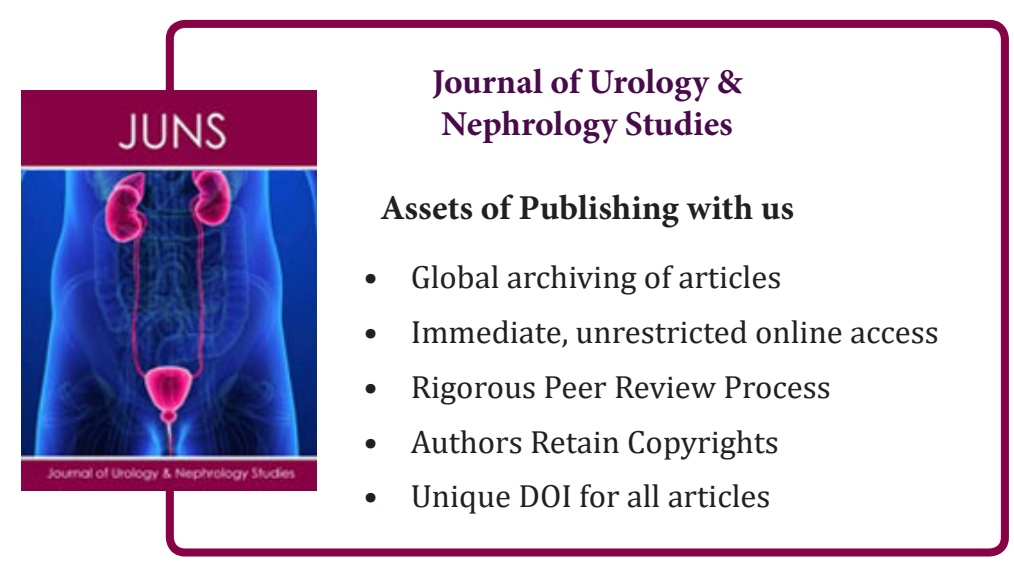

